\title{
Aplicação da técnica de deposição eletroforética para a obtenção de tubos cerâmicos de zircônia-ítria
}

\section{(Application of the electrophoretic deposition technique for obtaining yttria-stabilized zirconia tubes)}

\author{
E. Caproni, R. Muccillo \\ Centro de Ciência e Tecnologia de Materiais, Instituto de Pesquisas Energéticas e Nucleares, Travessa $R$ 400, \\ Cidade Universitária, São Paulo, SP 05508-900 \\ ecaproni@gmail.com,muccillo@usp.br
}

\begin{abstract}
Resumo
A técnica de deposição eletroforética (EPD) é reconhecida como a mais versátil para o processamento de materiais particulados devido ao seu baixo custo, à deposição em minutos e à conformação de corpos cerâmicos com geometria complexa. Neste trabalho foi feita uma montagem experimental que permite a conformação simultânea de 16 tubos cerâmicos por EPD. Partículas micrométricas de zircônia:ítria foram depositadas, após ajustes nas características reológicas da suspensão em isopropanol, em eletrodo de grafita na forma de tubo. Os tubos cerâmicos, após sinterização a $1500{ }^{\circ} \mathrm{C}$, foram caracterizados por difração de raios $\mathrm{X}$, microscopia de varredura por sonda, espectroscopia de impedância e resposta elétrica em função do teor de oxigênio. A técnica de EPD mostrou-se adequada para obtenção de tubos cerâmicos densos totalmente estabilizados na fase cúbica e resposta elétrica a diferentes quantidades de oxigênio de acordo com a lei de Nernst.
\end{abstract}

Palavras-chave: deposição eletroforética, zircônia:ítria, sensor de oxigênio.

Abstract

The electrophoretic deposition (EPD) is recognized as the most versatile technique for processing particulate materials, due to low cost, deposition in minutes and forming of pieces with complex geometry shapes. In this work an experimental setup for the simultaneous conformation of 16 ceramic tubes by EPD was built. Bimodal submicron yttria-stabilized zirconia particles were deposited into graphite electrodes, after suitably adjusting the rheological characteristics of the suspension in isopropanol. After graphite burning and YSZ sintering at $1500^{\circ} \mathrm{C}$, the ceramic tubes were characterized by X-ray diffraction, scanning probe microscope, impedance spectroscopy and electrical response as a function of oxygen content. Small dense one end-closed ceramic tubes, fully stabilized in the cubic phase, were successfully obtained by the EPD technique, showing the ability of that technique for processing large quantities of tubular solid electrolytes with electrical response to different amounts of oxygen according to the Nernst law.

Keywords: electrophoretic deposition, yttria-stabilized zirconia, oxygen sensor.

\section{INTRODUÇ̃̃O}

Nas ultimas décadas é crescente o interesse em desenvolvimento de eletrólitos sólidos à base de zircônia [13 ], pois estes materiais constituem um importante subgrupo dos condutores iônicos em uma ampla faixa de temperatura e pressão parcial de oxigênio, determinando o seu uso em várias aplicações eletroquímicas de alta temperatura [4]. Os eletrólitos sólidos podem ser projetados na forma de tubo fechado de um lado, para permitir a exposição de uma ampla área de contato entre o eletrólito sólido, o dispositivo eletroquímico e o meio de medida. Existem várias técnicas de conformação para a fabricação de tubos cerâmicos fechados de um lado, sendo as principais: compactação isostática, extrusão, moldagem por injeção, colagem por barbotina e deposição por eletroforese [5].

A técnica de deposição eletroforética (EPD) é reconhecida como a mais versátil para o processamento de particulados por causa da ampla faixa de dimensões possíveis, como por exemplo, em termos da espessura de depósitos que podem ser produzidos em comparação a outras técnicas, e também devido à sua aplicabilidade na conformação de pós nanométricos [6]. É também uma técnica rápida (deposição em minutos) e de baixo custo, permite a conformação de corpos cerâmicos com geometria complexa, em escala industrial, utilizando equipamentos simples.

Corpos cerâmicos são conformados por EPD a partir de uma suspensão estabilizada eletricamente e sob a influência de um campo elétrico. O processo de EPD ocorre em duas etapas [7-9]: na primeira as partículas carregadas eletricamente e dispersas em um líquido se movimentam para o eletrodo por meio da aplicação de um campo elétrico. $\mathrm{Na}$ segunda etapa, as partículas se aproximam o suficiente do eletrodo para coagularem e permanecerem depositadas, 
formando um compacto ou um filme denso e homogêneo. Em geral, o processo de EPD pode ser aplicado para qualquer sólido na forma de pó fino $(<30 \mu \mathrm{m})[8,9]$ ou para suspensão coloidal (pó fino entre $1 \mu \mathrm{m}$ e $0,001 \mu \mathrm{m}$ ) [8, 10-11] e solventes polares, pois estes apresentam uma forte interação com a superfície dos óxidos devido à característica iônica de interface óxido/solvente. Neste trabalho foi usado como meio de suspensão o solvente orgânico isopropanol, já que pós cerâmicos à base de zircônia apresentam um caráter isolante que pode dificultar o processo de deposição de paredes espessas para tensões baixas (eletrólise da água $\sim 2 \mathrm{~V}$ e formação de bolhas no deposito cerâmico). O prérequisito essencial para o sucesso da EPD é o carregamento elétrico das partículas sólidas suspensas. As cargas elétricas são originadas da dissociação dos íons e/ou da adsorção (física ou química) de componentes iônicos sob a superfície da partícula, criando uma dupla camada elétrica. A dupla camada elétrica tem como função estabilizar as partículas suspensas (estabilização eletrostática) e permitir a movimentação das partículas no campo elétrico [12].

Depositar pós cerâmicos em um metal (ou em um substrato condutor) por EPD é relativamente simples, mas o fator mais importante é a forma de evitar trincas no depósito cerâmico durante a secagem e sinterização. Uma das maneiras de se evitar trincas no deposito cerâmico é o aumento do tamanho médio de partículas, já que partículas muito finas diminuem a densidade de empacotamento do depósito resultando em trincas durante a secagem. Com o aumento do tamanho de partículas é possível melhorar o empacotamento das partículas, obtendo depósitos mais estáveis [13].

A zircônia estabilizada com 8 mol\% ítria é uma cerâmica amplamente utilizada como eletrólito sólido em sensores de oxigênio $[14,15]$ e em células à combustível [16] devido a sua alta condutividade iônica em temperaturas maiores que $400{ }^{\circ} \mathrm{C}$, e tem sido estudada para fabricação na forma de filmes [17] e de peças cerâmicas [18]. Neste trabalho, suspensões cerâmicas de $\mathrm{ZrO}_{2}: 8 \mathrm{~mol} \% \mathrm{Y}_{2} \mathrm{O}_{3}$ com diferentes tamanhos de partículas foram preparadas em meio de isopropanol e adição de dispersante. O principal objetivo é o estudo de conformação por EPD de tubos cerâmicos fechados de um lado para serem usados como sensor de oxigênio a altas temperaturas $\left(>800^{\circ} \mathrm{C}\right)$.

\section{MATERIAIS E MÉTODOS}

O pó cerâmico utilizado neste trabalho foi $\mathrm{ZrO}_{2}: 8 \mathrm{~mol} \%$ $\mathrm{Y}_{2} \mathrm{O}_{3}$ (TZ-8Y, Tosoh, EUA) na forma de grânulos com área de superfície especifica $16 \pm 3 \mathrm{~m}^{2} / \mathrm{g}$. Parte desse material foi calcinado a $850{ }^{\circ} \mathrm{C} / 1 \mathrm{~h}$ para aumentar o tamanho dos grânulos. As características dos pós foram analisadas por espalhamento a laser (Cilas granulômetro 1064) para determinar a distribuição de tamanho de grânulos, Tabela I. $\mathrm{D}_{50}$ é o tamanho médio dos grânulos a $50 \%$ da amplitude de freqüência na curva de distribuição do tamanho de grânulos.

Para a preparação das suspensões cerâmicas foi utilizado isopropanol $(99,5 \%$ CAAL) como solvente e o ácido
Tabela I - Tamanho médio dos grânulos do pó cerâmico TZ$8 \mathrm{Y}$ antes e após calcinação a $850^{\circ} \mathrm{C} / 1 \mathrm{~h}$.

[Table I - Granule average size of TZ-8Y powders before and after calcination at $850^{\circ} \mathrm{C} / \mathrm{lh}$.]

\begin{tabular}{cc}
\hline Material & $\mathrm{D}_{50}(\mu \mathrm{m})$ \\
\hline TZ-8Y & 0,75 \\
TZ-8Y após calcinação a $850{ }^{\circ} \mathrm{C} / 1 \mathrm{~h}$ & 19,5 \\
\hline
\end{tabular}

4-hidroxibenzóico ( $\geq 99 \%$ Fluka) como dispersante.

Para a medida da mobilidade eletroforética (ESA 9800 Matec Appl. Sci.) das partículas de TZ-8Y em função da concentração do dispersante, foi preparada uma dispersão de uma mistura de $70 \%$ em peso de TZ-8Y $(0,75 \mu \mathrm{m})$ e $30 \%$ de TZ-8Y $(19,5 \mu \mathrm{m})$ em isopropanol, na concentração de $1 \%$ em volume dos pós, para avaliar a estabilidade da suspensão cerâmica e o efeito de geração de cargas na superfície das partículas cerâmicas com a variação do teor do dispersante. A razão dispersante/isopropanol foi $5 \mathrm{~g} / 100 \mathrm{~mL}$.

Para a obtenção de tubos cerâmicos de zircônia:ítria foi confeccionado um sistema que permite a deposição eletroforética de 16 tubos simultâneos $(4 \mathrm{~mm} \times 30 \mathrm{~mm}$, cada), conforme Fig. 1. O sistema consiste de uma cuba de aço com capacidade de aproximadamente $230 \mathrm{~mL}$ de suspensão, que atua como anodo, na qual é colocada a suspensão com as partículas do material cerâmico a ser depositado. O eletrodo de grafita (catodo) na forma de tubo de aproximadamente $3 \mathrm{~mm}$ de diâmetro $(99,9995 \%$ graphite rod, Alfa Aesar) é fixado em uma chapa de aço com 16 furos de aproximadamente $3 \mathrm{~mm}$ de diâmetro cada. Uma fonte de tensão dc (Hewlett Packard 6116A), que opera na faixa de

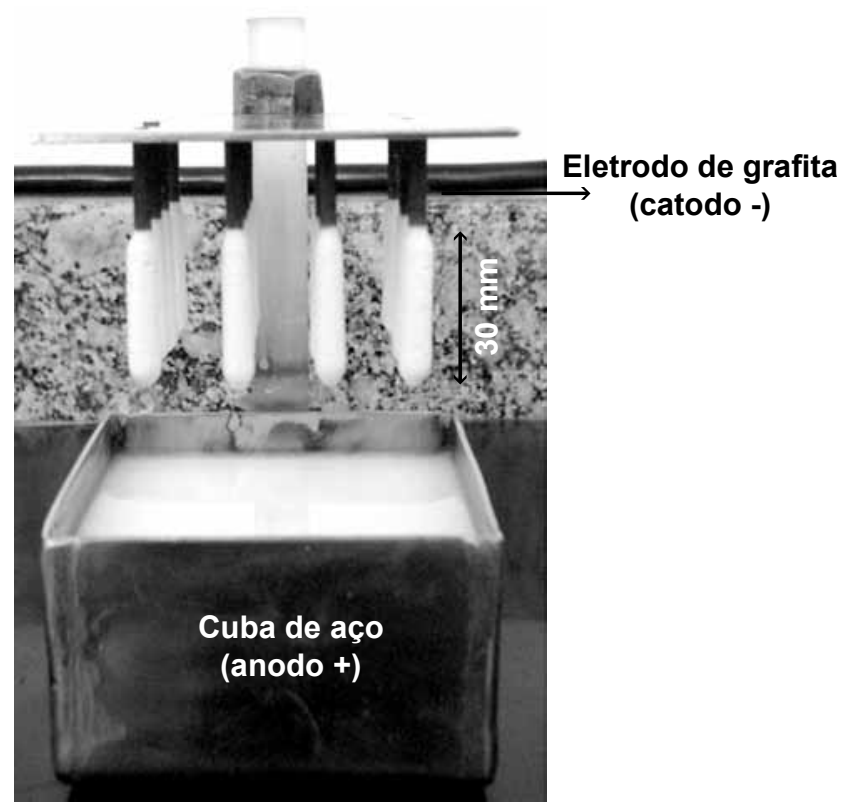

Figura 1: Foto do sistema confeccionado para EPD simultânea de 16 tubos cerâmicos de TZ-8Y.

[Figure 1: Picture of the experimental setup for simultaneous conformation of 16 8YSZ ceramic tubes by EPD.] 
0 a $100 \mathrm{~V}$ com controle de corrente, foi usada para aplicar a tensão entre a cuba e a grafita, para promover a deposição das partículas cerâmica na grafita.

Para os testes de obtenção de tubos cerâmicos pelo processo de EPD foram usadas suspensões cerâmicas preparadas na proporção de $10 \%$ em volume de sólidos TZ$8 \mathrm{Y}(70 \% 0,75 \mu \mathrm{m}$ e $30 \% 19,5 \mu \mathrm{m})$, tendo como solvente isopropanol. Cada suspensão foi homogeneizada em ultrasom por $30 \mathrm{~min}$ com $3 \% \mathrm{em}$ peso de dispersante (em relação ao pó).

A deposição eletroforética das partículas cerâmicas foi feita com tensão constante de $80 \mathrm{~V}$ por 2 min. Essa tensão e tempo foram suficientes para promover a deposição das partículas cerâmicas no eletrodo de grafita. Os tubos foram secos ao ar e sob atmosfera de $\mathrm{KCl}$ ( $\sim 85 \%$ de umidade) e submetidos ao processo de sinterização. O perfil utilizado foi de $900{ }^{\circ} \mathrm{C} / 2 \mathrm{~h}$ (eliminação da grafita) com taxa de aquecimento $2{ }^{\circ} \mathrm{C} / \mathrm{min}$, seguindo até $1500{ }^{\circ} \mathrm{C} / 0,5 \mathrm{~h}$, com a mesma taxa. A taxa de resfriamento foi $2{ }^{\circ} \mathrm{C} / \mathrm{min}$.

Os tubos cerâmicos sinterizados foram seccionados transversalmente e as secções na forma de anéis cilíndricos de $\sim 2 \mathrm{~mm}$ foram caracterizados por meio de determinação da densidade aparente pelo método de Arquimedes de imersão em água, difração de raios $\mathrm{X}$ (difratômetro BrukerAXS D8 Advance com radiação Cu-k $\alpha, 40 \mathrm{kV}, 40 \mathrm{~mA}$ ) para determinação das fases cristalinas e espectroscopia de impedância a $400{ }^{\circ} \mathrm{C}$ (analisador de impedância Hewlett Packard 4192A, $100 \mathrm{mV}$ de sinal ac na faixa de freqüências de $5 \mathrm{~Hz}$ a $13 \mathrm{MHz}$ ) para determinação da resistividade elétrica.

A superfície do tubo cerâmico, seco em atmosfera de $\mathrm{KCl}$ e sinterizado a $1500{ }^{\circ} \mathrm{C}$, foi polida e atacada termicamente a $1400{ }^{\circ} \mathrm{C} / 20$ min e observada em microscópio de varredura por sonda (Jeol JSPM-5200) em modo de contato, com tamanho de imagem $10 \mu \mathrm{m} \times 10 \mu \mathrm{m}$.

Para análise da resposta elétrica em função do teor de oxigênio, o tubo cerâmico foi pintado interna e externamente com platina coloidal (Demetron 308A). Em contato com o eletrodo de platina foram colocados fios de liga $\mathrm{Ni}-\mathrm{Cr}$. O tubo cerâmico foi colocado dentro de um tubo de quartzo e foi feita a selagem com cimento refratário para separar a superfície de medida (gás vetor, Argônio) e a superfície

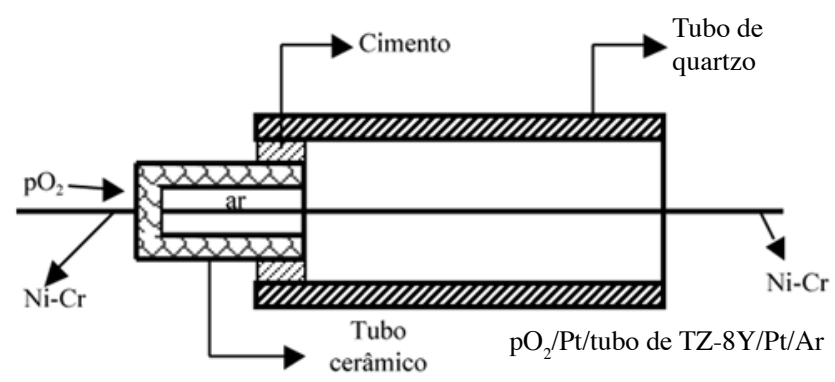

Figura 2: Esquema do arranjo experimental para medidas elétricas da célula $\mathrm{pO}_{2} / \mathrm{Pt} /$ tubo de $\mathrm{TZ}-8 \mathrm{Y} / \mathrm{Pt} / \mathrm{ar}$.

[Figure 2: Scheme of the experimental setup for electrical measurements of the $\mathrm{pO}_{2} / \mathrm{Pt}$ /tubular 8YSZ/Pt/air cell.] de referência (ar) obtendo-se um arranjo experimental para medidas elétricas, conforme Fig. 2. O arranjo foi montado dentro de um forno tubular a $850{ }^{\circ} \mathrm{C}$ acoplado a um sistema que permite controlar a pressão parcial de oxigênio $\left(\mathrm{pO}_{2}\right)$ na amostra. Esse sistema consiste basicamente de uma bomba eletroquímica de oxigênio e um sensor de oxigênio composto por um eletrólito sólido de zircônia:ítria na forma de um tubo fechado em uma de suas extremidades [19], operando na faixa de 6-650 ppm.

\section{RESULTADOS E DISCUSSÃO}

A Fig. 3 mostra a dependência da mobilidade eletroforética dos grânulos de TZ-8Y em isopropanol em função da concentração do dispersante. $O$ valor da mobilidade eletroforética das partículas em isopropanol a um $\mathrm{pH}=6,9$ é de $0,265 \times 10^{-8} \mathrm{~m}^{2} / \mathrm{Vs}$. O carregamento elétrico, espontaneamente, pode ser explicado pela pequena quantidade de $\mathrm{H}_{2} \mathrm{O}$ encontrada no solvente utilizado [20]. Uma pequena quantidade de água no álcool gera íons $\mathrm{H}^{+} \mathrm{e}$ $\mathrm{OH}^{-}$por dissociação eletrolítica [21]. Com base no resultado, o íon $\mathrm{H}^{+}$foi adsorvido na superfície das partículas do pó cerâmico. Isto significa que a mobilidade eletroforética é influenciada pela adsorção do íon $\mathrm{H}^{+}$nas partículas em meio alcoólico, já que o íon $\mathrm{H}^{+}$se comporta como o íon determinante de potencial. A quantidade de íons gerados e o comportamento dos íons adsorvidos na superfície da partícula são dependentes do tipo de álcool usado.

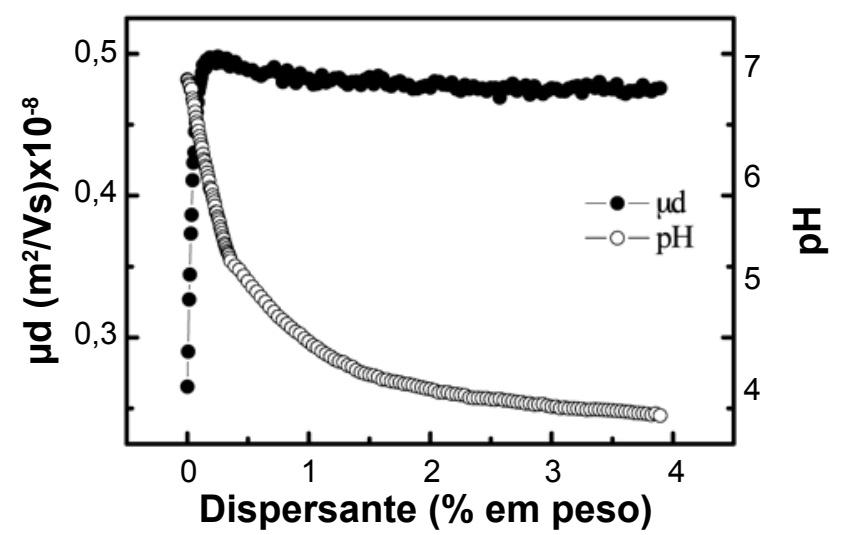

Figura 3: Mobilidade eletroforética das partículas de TZ-8Y em função da concentração do dispersante (ácido 4- hidroxibenzóico) em suspensão de isopropanol.

[Figure 3: Electrophoretic mobility of 8YSZ particles as a function of dispersant (4-hydroxybenzoic acid) content in isopropanol suspensions.]

Esse resultado mostra que a simples adição do pó cerâmico de TZ-8Y em isopropanol e a homogeneização em ultra-som por $30 \mathrm{~min}$, já são suficientes para produzir o carregamento elétrico na superfície das partículas, produzindo a repulsão eletrostática para estabilizar a suspensão. Porém, para garantir uma maior estabilidade da suspensão durante o processo de EPD, é necessária a adição de dispersante. A adsorção específica do dispersante à interface sólido/ 
solvente aumenta a mobilidade dinâmica das partículas, conforme mostra a Fig. 3. Esse aumento proporciona maior repulsão entre as partículas, promovendo uma melhor dispersão da suspensão. Esse efeito é verificado até que se atinja uma quantidade de $\sim 0,25 \%$ do polieletrólito, acima da qual a mobilidade permaneça constante e todo o dispersante adicionado passa a contribuir para o aumento da força iônica da solução $[10,22]$.

Para a preparação das suspensões cerâmicas para EPD das partículas de TZ-8Y em eletrodo de grafita foi escolhida a concentração de $3 \%$ em peso do dispersante. A Fig. 4 mostra os tubos obtidos por EPD após secagem ao ar e em meio de $\mathrm{KCl}$, enquanto que a Fig. 5 os tubos após sinterização a $1500{ }^{\circ} \mathrm{C}$.

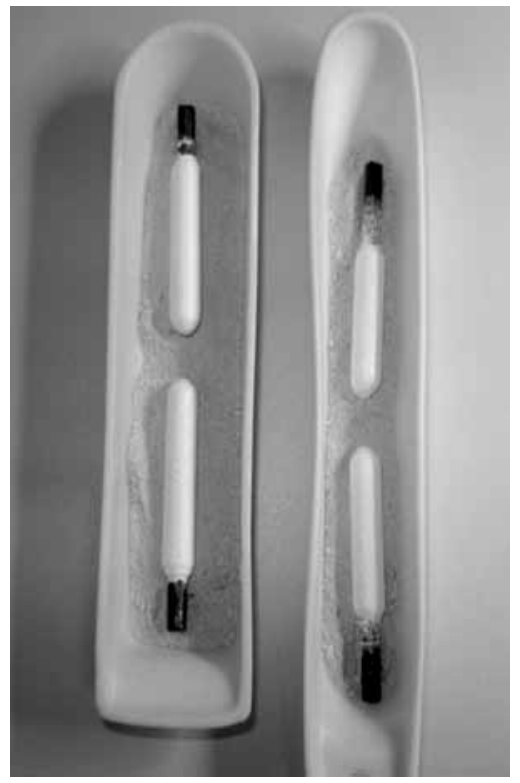

Figura 4: Tubos cerâmicos obtidos por EPD após secagem em meio de $\mathrm{KCl}$ (esquerda) e ao ar (direita).

[Figure 4: Ceramic tubes obtained by EPD after drying in $\mathrm{KCl}$ (left) and air (right).]
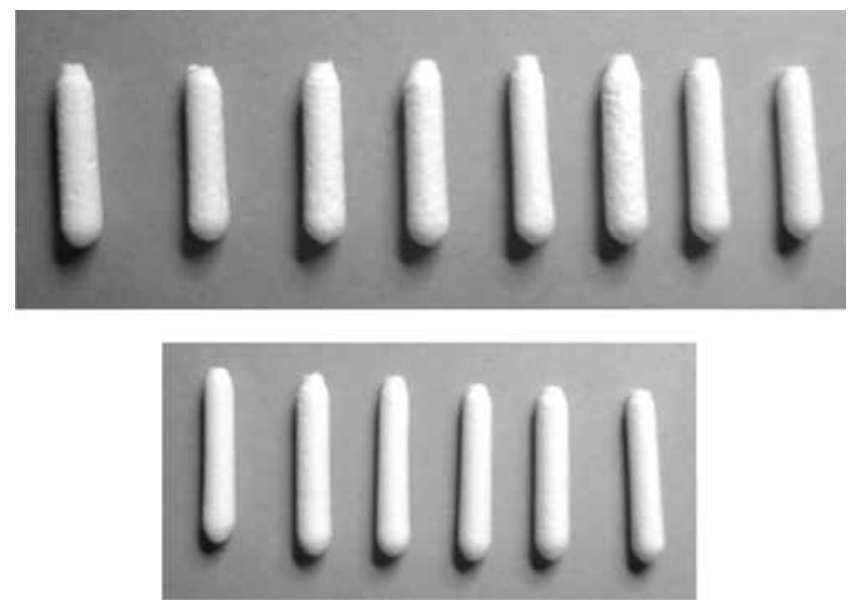

Figura 5: Tubos cerâmicos fechados de um lado de TZ-8Y obtidos por EPD, após a secagem ao ar (superior) e em meio de $\mathrm{KCl}$ (inferior), e sinterizados a $1500{ }^{\circ} \mathrm{C} / 0,5 \mathrm{~h}$.

[Figure 5: One-end closed 8YSZ tubes obtained by EPD, after drying in air (top) and $\mathrm{KCl}$ (bottom), and sintered at $1500^{\circ} \mathrm{C} / 0.5 \mathrm{~h}$.]
A Fig. 6 mostra os difratogramas de raios $\mathrm{X}$ das secções dos tubos cerâmicos obtidos por EPD. Os corpos cerâmicos apresentam picos correspondentes à fase cúbica $(2 \theta=$ $30,05^{\circ}, 111,100 \%$ ), não havendo diferença na formação de fases cristalinas pelo meio de secagem utilizada após o processo de EPD. Os tubos cerâmicos sinterizados apresentam valores de densidade aparente superiores a $92 \%$ da densidade teórica. Este resultado mostra que a densificação atingida é suficiente para que o material possa ser utilizado como eletrólito sólido em sensores de oxigênio, evitando que durante o funcionamento do sensor, moléculas de $\mathrm{O}_{2}$ do gás sob análise difundam pelos poros do eletrólito sólido acarretando erro na avaliação da concentração de oxigênio.

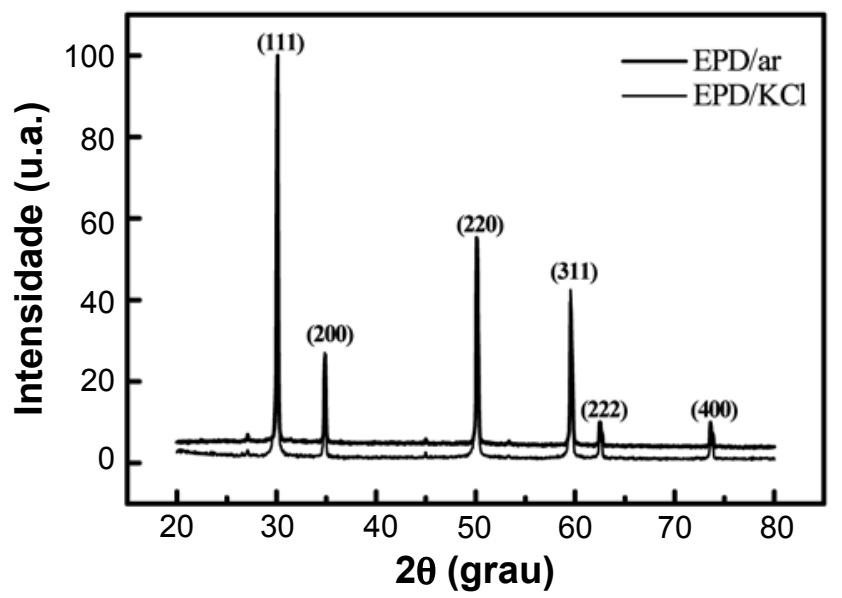

Figura 6: Difratogramas de raios X dos eletrólitos sólidos de TZ$8 Y$ obtidos por EPD.

[Figure 6: X-ray diffraction patterns of $8 Y S Z$ solid electrolytes obtained by EPD.]

Os diagramas de impedância, medidos a $\sim 400{ }^{\circ} \mathrm{C}$, das secções dos tubos cerâmicos, secos ao ar e em meio de $\mathrm{KCl}$, e sinterizados a $1500{ }^{\circ} \mathrm{C}$, são mostrados na Fig. 7. Há dois semicírculos bem definidos, um a altas freqüências $(\mathrm{AF})$, relacionado às propriedades intragranulares e outro a baixas freqüências $(\mathrm{BF})$, relacionado à resistividade devida

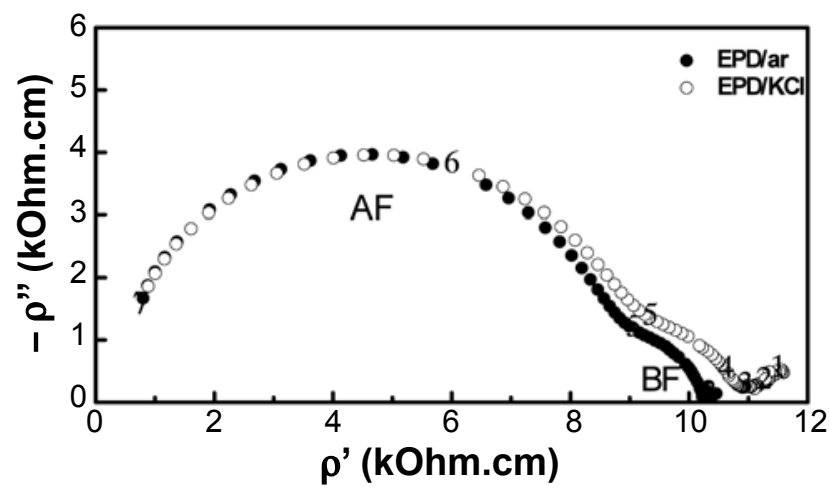

Figura 7: Diagramas de impedância medidos a $400{ }^{\circ} \mathrm{C}$ dos eletrólitos de TZ-8Y obtidos por EPD e sinterizados.

[Figure 7: Impedance diagrams, measured at $400{ }^{\circ} \mathrm{C}$, of the sintered 8YSZ electrolyte obtained by EPD.] 
ao bloqueio dos portadores de carga nos contornos de grão (ou resistividade intergranular), com resistividade total $10,2 \mathrm{k} \Omega . \mathrm{cm}$ para a amostra seca ao ar e $\sim 11 \mathrm{k} \Omega . \mathrm{cm}$ para a seca em KCl. Há uma pequena diferença entre os diagramas de impedância dos tubos cerâmicos, porém os valores de resistividade total para ambos os tubos são similares aos encontrados em sensores comerciais preparados por extrusão.

Como não houve uma mudança significativa nas propriedades estruturais e elétricas dos tubos cerâmicos em relação ao meio de secagem adotado, foram escolhidos para dar continuidade os tubos cerâmicos secos em meio de $\mathrm{KCl}$ e sinterização a $1500{ }^{\circ} \mathrm{C}$. A Fig. 8 mostra a imagem obtida por microscópio de varredura por sonda da superfície da secção do tubo cerâmico polida e atacada termicamente. A adição de partículas grossas à matriz de partículas finas modifica a morfologia e o tamanho médio de grão da cerâmica após o processo de sinterização. As amostras apresentam tamanho médio de grão 1-5 $\mu \mathrm{m}$, típico da zircônia totalmente estabilizada, além da baixa porosidade, estando de acordo com os valores de densidade aparente.

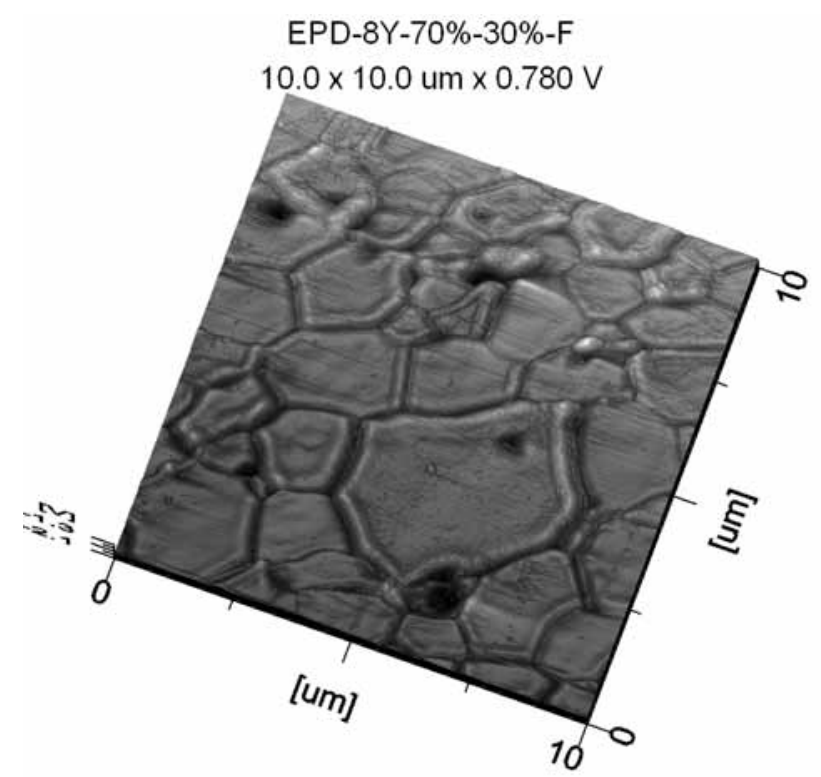

Figura 8: Imagem topográfica obtida por microscopia de varredura por sonda da superfície polida e atacada da secção de tubo de TZ$8 Y$ preparado por EPD.

[Figure 8: Dynamic force microscopy topographic image of a polished and etched surface of a section of the sintered 8YSZ tube prepared by EPD.]

Medidas da estabilização da força eletromotriz (E) em função da temperatura em atmosfera de argônio (atmosfera escolhida por conter baixo teor de oxigênio, $<3$ ppm, que já dá uma indicação da capacidade sensorial do tubo cerâmico) foram feitas na faixa de temperatura ambiente a $600{ }^{\circ} \mathrm{C}$ durante $0,2 \mathrm{~h}$ para a queima e eliminação de orgânicos provenientes do cimento usado para a selagem do tubo cerâmico em tubo de quartzo, seguindo até $850^{\circ} \mathrm{C}$, conforme mostra a Fig. 9. Na temperatura de $850{ }^{\circ} \mathrm{C}$ E se mantém constante e próxima a $\sim-184 \mathrm{mV}$, mostrando a diferença

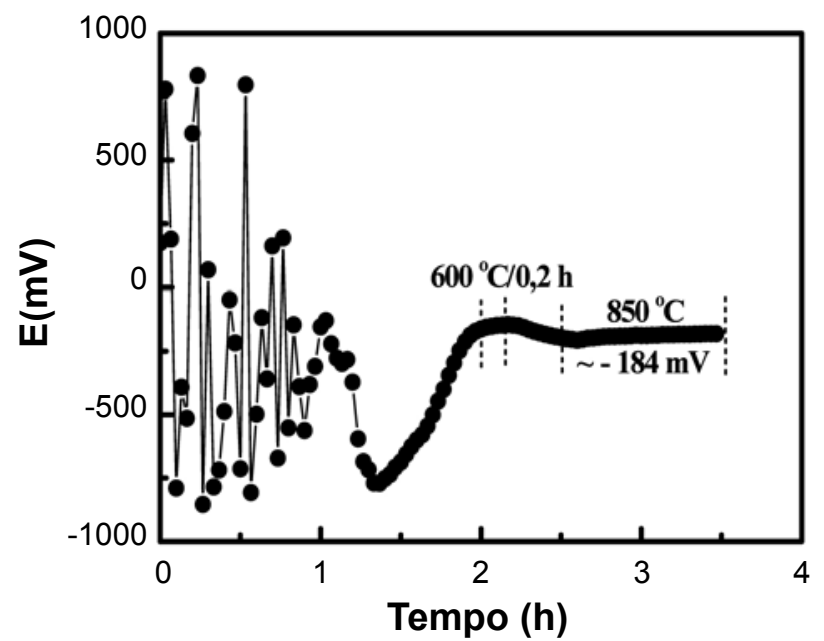

Figura 9: Dependência da força eletromotriz com a temperatura do tubo cerâmico de zircônia:ítria em atmosfera de argônio (baixo teor de oxigênio); referência: ar.

[Figure 9: Dependence of the electromotive force signal on the temperature of the yttria-stabilized zirconia in argon (low oxygen content); air reference.]

da pressão parcial de oxigênio entre a superfície externa e interna da célula argônio/Pt/tubo cerâmico/Pt/ar. Assim, foi escolhida a temperatura de $850{ }^{\circ} \mathrm{C}$ para as medidas elétricas do tubo cerâmico sob diferentes teores de oxigênio.

A Fig. 10 mostra a variação do sinal elétrico E para diferentes teores de oxigênio (60-650 ppm) com tempo de resposta de $\sim 1 \mathrm{~min}$. A força eletromotriz gerada através do eletrólito sólido é proporcional ao logaritmo da concentração das espécies moveis (vacâncias de oxigênio) de acordo com a lei de Nernst. A Fig. 11 mostra esta dependência para o tubo cerâmico obtido por EPD e para o sensor utilizado no sistema de $\mathrm{pO}_{2}$, evidenciando o bom funcionamento do sensor de oxigênio construído com tubo cerâmico de zircônia:ítria obtido por EPD.

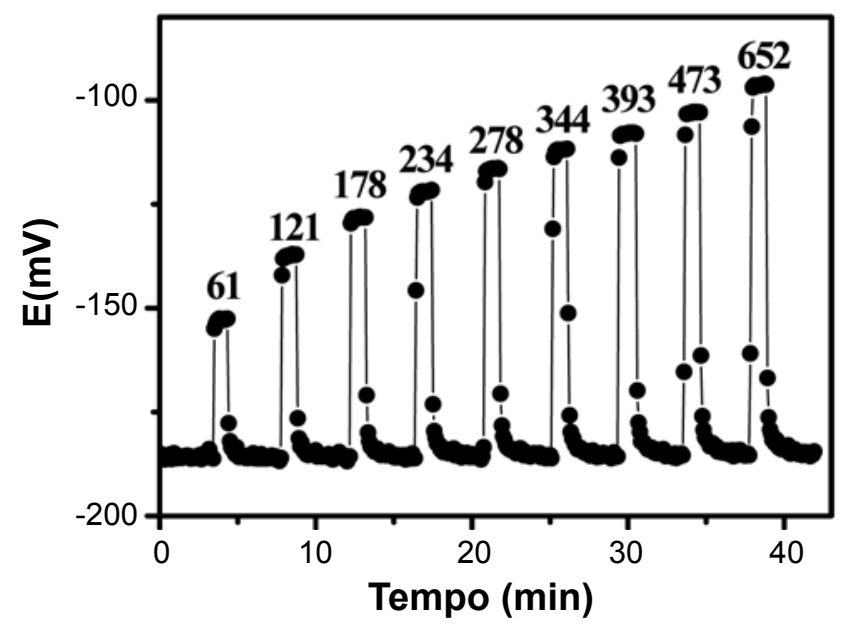

Figura 10: Resposta da força eletromotriz do eletrólito sólido TZ8 Y na forma de tubo para diferentes teores de oxigênio de $\sim 60$ a $\sim 650 \mathrm{ppm}$ a $850^{\circ} \mathrm{C}$.

[Figure 10: Electromotive force signal response of the electrophoretic deposited $8 Y S Z$ solid electrolyte tubes for oxygen level inputs in the 60-650 ppm range at $850^{\circ} \mathrm{C}$.] 


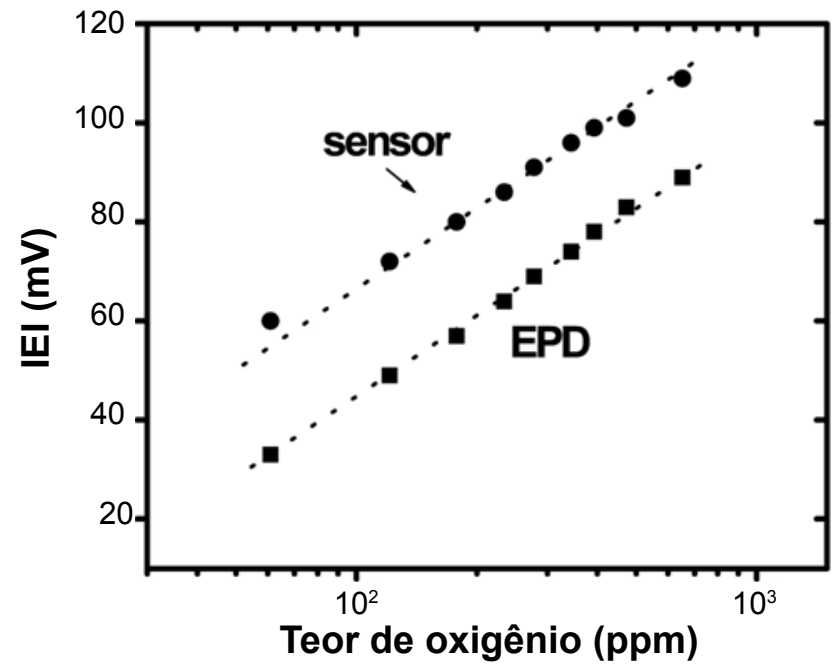

Figura 11: Dependência da força eletromotriz do eletrólito sólido TZ-8Y, obtido por deposição eletroforética na forma de tubo, em função do logaritmo do teor de oxigênio.

[Figure 11: Dependence of the electromotive force of the electrophoretic deposited $8 Y S Z$ solid electrolyte tube on the logarithm of the oxygen content.]

\section{CONCLUSÕES}

A técnica de deposição eletroforética foi usada para a preparação de eletrólitos sólidos de TZ-8Y na forma de tubos. As suspensões cerâmicas para a EPD foram preparadas pela mistura de partículas de TZ-8Y (70\% em peso de partículas de $0,75 \mu \mathrm{m}$ e $30 \%$ de $19,5 \mu \mathrm{m}$,) em isopropanol, mostrando que a mistura de partículas finas e grossas é suficiente para evitar trincas durante a secagem dos tubos cerâmicos. A adição do ácido 4-hidroxibenzóico como dispersante aumenta a mobilidade eletroforética das partículas de TZ$8 \mathrm{Y}$ em suspensão, promovendo condições adequadas para o processo de EPD em eletrodo de grafita. Tubos cerâmicos de TZ-8Y densos e sem trincas foram obtidos pela técnica de EPD, mostrando a habilidade da técnica para a conformação de peças cerâmicas de geometria complexa, em larga escala e com propriedades estruturais e elétricas adequadas para aplicações em dispositivos sensores de oxigênio.

\section{AGRADECIMENTOS}

À FAPESP (Procs. 05/53241-9 e 06/61025-7) e ao CNPq (Proc. 306496/88).

\section{REFERÊNCIAS}

[1] E. C. Subbarao, "Zirconia - an Overview", in Advances in Ceramics, Vol. 3, Science and Technology of Zirconia I, eds.
A. H. Heuer, L. W. Hobbs, The Am. Ceram. Soc. (1981) 1. [2] R. M. Dell, A. Hooper, "Oxygen Ion Conductors", in Solid Electrolytes, Eds. P. Hagenmuller, W. Van Gool, Academic Press, N. York, EUA (1978) 291.

[3] N. Yamamoto, H. Yanagida, Science and Technology of Zirconia III, Advances in Ceramics, Vol. 24, The Am. Ceram. Soc. (1988).

[4] S. C. Singhal, MRS Bull. 25 (2000) 16-21.

[5] D. W. Richerson, Modern Ceramic Engineering, $2^{\text {nd }}$ Ed., Marcel Dekker, Inc., EUA (1992) Cap. 10.

[6] A. R. Boccaccini, J. A. Roether, B. J. C. Thomas, M. S. P. E. Chavez, E. Stoll Shaffer, E. J. Minay, J. Ceram. Soc. Japan 114, 1 (2006) 1-14.

[7] A. R. Boccaccini, I. Zhitomirsky, Curr. Opinion Solid State Mater. Sci. 6 (2002) 251-260.

[8] O. O. Van der Biest, L. J. Vandeperre, Annu. Rev. Mater. Sci. 29 (1999) 327-352.

[9] I. Corni, M.P. Ryan, A. R. Boccaccini, J. Eur. Ceram. Soc. 28, 7 (2008) 1353-1367.

[10] I. R. Oliveira, A. R. Studart, R. G. Pileggi, V. C. Pandolfelli, Dispersão e Empacotamento de Partículas - Princípios e Aplicações em Processamento Cerâmico, Fazendo Arte Editorial, S. Paulo (2000).

[11] J. A. Lewis, J. Am. Ceram. Soc. 83, 10 (2000) 23412359.

[12] F. Harbach, H. Nienburg, J. Eur. Ceram. Soc. 18, 6 (1998) 675-683.

[13] S. Hayashi, C. Sato, Z. Nakagawa, J. Mater. Sci. 41, 24 (2006) 8068-8073.

[14] R. Ramamoorthy, P. K. Dutta, S. A. Akbar, J. Mater. Sci. 38, 21 (2003) 4271-4282.

[15] A. M. Azad, S. A. Akbar, S. G. Mhaisalkar, L. D. Birkefeld, K. S. Goto, J. Electrochem. Soc. 139, 12 (1992) 3690-3704.

[16] S. P. S. Badwal, K. Foger, Ceram. Int. 22, 3 (1996) $257-$ 265.

[17] L. Jia, Z. Lu, X. Q. Huang, Z. G. Liu, Z. Zhi, X. Q. Sha, G. Li, W. Su, Ceram. Int. 33, 4 (2007) 631-635.

[18] L. Besra, T. Uchikoshi, T. S. Suzuki, Y. Sakka, J. Am. Ceram. Soc. 91, 10 (2008) 3154-3159.

[19] M. C. Steil, F. C. Fonseca, Y. V. França, J. F. Q. Rey, E. N. S. Muccillo, R. Muccillo, Cerâmica 48, 307 (2002) 146-152.

[20] R. H. R. Castro, P. J. B Marcos, E. K. Sakamoto, D. Gouvêa, J. Mater. Sci. 42, 16 (2007) 6946-6950.

[21] H. Negishi, K. Yamaji, N. Sakai, T. Horita, H. Yanagishita, H. Yokokawa, J. Mater. Sci. 39, 3 (2004) 833838.

[22] Y. Hirata, A. Nishimoto, Y. Ishihara, J. Ceram. Soc. Japan 100 (1992) 972-978.

(Rec. 14/05/2011, Rev. 03/11/2011, Ac. 10/11/2011) 